\title{
O PREPARO PARA O AUTOCUIDAdO dO CLIENTE DIABÉtICO E FAMILIA*
}

\author{
Margareta Luce ** \\ Maria Itayra Padilha $* * *$ \\ Regina Lucia Valiatti de Almeida **** \\ Mariângela Oliveira da Silva $* * * * *$
}

\begin{abstract}
RESUMO - Relato parcial, quanti-qualitativo, de de pesquisa-ação realizada em unidade de internação piloto/ambulatório do Hospital de Ensino, extensivo a moradia. Objetivo: estabelecer modelos de integração hospital/comunidade, visando o indivfduo na unidade familiar, face à recuperação/reabilitação e integração ao trabalho/sociedade, considerando os problemas da moradia/trabalho e aplicando a aproposição do SUDS na extensão das ações hospitalares a comunidade. Visitas domiciliares levantam as condições da moradia, consolidando a participação familiar no processo. Durante a internacção os cuidados de enfermagem realizados são orientados, conduzindo à participação e à realização destes, pelo cliente e familiares.
\end{abstract}

\begin{abstract}
Partial report, quantity=quality, of action-reserch developed in the ward tesambulatory of a University Hospital, extensive to home; integrating students, teachers and nursing team. Objective: to establish standards to integrate hospital/community, seeking the man in the home circle, oppose the recovery/rehabilitation and the integration to work/society, considering the problems in the home/work and put into practice the proposition of the SUDS with extension to the hospital/ community actions. Home visits raising the home conditions, family and/or community, consolidating the participation of them in the process. During the interm, the nursing care oriented to conduct to the participation and realization of the care by the client and relatives happining the same in the ambulatory probation.
\end{abstract}

\section{INTRODUÇÃO}

O autocuidado como suporte educativo já existe como proposta de assistência desde o surgimento da enfermagem moderna, porém a ênfase maior foi dada a partir da teoria do Autocuidado de OREM (1980), cuja premissa básica é a crença de que o homem tem habilidades inatas para cuidar de si mesmo, e que se pode beneficiar com o cuidado da equipe de saúde quando apresenta limitações decorrentes da falta de saúde. O autocuidado representa a forma de despaternalizar a assistência, tornando-a participativa.

A equipe de saúde tem, pois, o papel de desenvolver as habilitades de autocuidado nos clientes, deixando-lhes o direito de decidir sobre a mudança de comportamento. Esta $\varepsilon$ uma atitudade extremamente diffcil, já que sde aprende o tempo todo que "somos os responsáveis pelo cuidar". NORONHA (1986).

As vantagens do autocuidado são muitas, porém, com maior relevância, está a otimização da relação custo/benefficio, alcançada, entre outras consequências, por maior independência do cliente, e diminuição de suas reinternaçőes.

Escolheu-se o cliente diabético para a preparação do autocuidado, devido a ser uma doença crónica e que, no decorrer de sua história, $\varepsilon$ acompanhada de várias complicações, necessitando portanto de cuidados constantes por parte do portador e seus familiares, bem como, por ter sido criado o Plano Nacional de Prevenção e Controle do Diabetes Mellius do Ministerio da Saúde.

Conforme JADZINSKY (1987) e PERRASE (1987), a educação para o autocuidado visa mudanças de atitudes do diabético, a fim de serem atingidos trés objetivos fundamentais: a) identificação de seus temores e ansiedades; 2) aquisição de hábitos; e 3) aprendizagem de habilidades.

O trabalho está sendo realizado pelo Departamento de Metodologia da escola de Enfermagem Anna Nery - EEAN, em conjunto com o Serviço de desenvolvimento da Divisão de Enfermagem do Hospital de Ensino da Universidade Federal do Rio de Janeiro (UFRJ), em uma unidade de internação piloto, em que os profissionais lotados demonstraram interesse em participar, sendo trabalhados para tal.

Inicia-se o programa de autocuidado ao cliente a partir do momento em que este apresente condiçōes metab6licas e emocionais de participar das sessőes de

\footnotetext{
* Prêmio Lais Neto dos Reis - 1 lugar -41 Congresso Brasileiro de Enfermagem - Florianopolis - Santa Catarina

** Professor Adjunto da Escola de Enfermagem Anna Nery/Universidade Federal do Rio de Janeiro. Departamento de Metodologia.

**** Professor Assistente da Escola de Enfermagem Ańna Nery/Universidade Federal do Rio de Janeiro. Departamento de Metodologia.

**** Enfermeira Licenciada. Auxiliar da Pesquisa.

***** Enfermeira Chefe de Setor do Hospital Universitário Clementino Fraga Filho - Universidade Federal do Rio de Janeiro.
} 
orientação, as quais são realizadas individualmente e em grupo. Durante todo o processo a famnlia e/ou comunidades são consideradas como participantes efetivas. ZAGUR Y et alii (1984) afirmam que "em nenhuma outra doença, o controle depende tanto da aprendizagem sobre a natureza da doença, os princípios em que se baseia o tratamento, as normas dietéticas gerais, assim como as vantagens da insulina ou dos hipoglicemiantes orais, entre outros fatores. Fundamentalmente, a instrução leva à compreensão de que, se existe alguma doença na qual a pessoa portadora pode influir decisivamente sobre o seu futuro, esta $e$ a Diabetes Mellius".

Realiza-mse também, visitas domiciliares, durante a hospitalização do cliente, a fim de serem conhecidas as condições ambientais e familiares que afetam o preparo para o autocuidado a ser desenvolvido em bases realísticas, é marcada outra visita após a alta, destinada à supervisão do autocuidado e preenchimento das lacunas existentes na sua execução. Estas visitas levam em conta a afirmação de MENDES (1975) de que, quando "na entrevista no ambulatório, a clientela afimmava saber adquirir, preparar e administrar a insulina corretamente e na observação destas atividades no domicllio, concluiu-se que, dos cinquenta visitados apenas dois (4\%) haviam agido corretamente."

Quando o paciente recebe alta, apraza-se o retorno ao ambulatório para consultas médicas, de enfermagem e de nutrição, com a finalidade de se avaliar e enfatizar os pontos críticos do autocuidado e propiciar meios para resolução de novos problemas surgidos.

Serão apresentados os resultados parciais das atividades acima descritas, referentes ao período de julho a dezembro de 1988 , tendo sido atendidos 42 pacientes e 14 famnias. É importante ressaltar que a pesquisa ainda se encontra em andamento.

\section{OBJETIVOS}

- Oferecer aos graduados e poe-graduados experiência de prática profissional, com o cliente diabético e seus familiares, voltados para a metodologia do autocuidado.

- Apresentar a linha de pesquisa-ação aos estudantes e enfermeiros de pós-graduação, levando-os a propor soluções para os problemas encontrados na comunidade.

- Utilizar o Sistema Unificado Descentralizado da Saúde na extensão das ações hospitalares à comunidade, visando ao autocuidado do cliente e/ou famnia/comunidade.

- Atender com tecnologia apropriada, as necessidades da clientela.

- Identificar prováveis diabéticos e hipertensos através da avaliação sistemçatica, no primeiro contato com os familiares.

\section{MEDOLOGIA}

É utilizada a pesquisa-ação, na qual THIOLLENT (1986) refere ser necessária a participação das pessoas implicadas nos problemas investigados.

- Critério para seleção da clientela - Serem diabéticos do tipo I ou II, moradores da área programática (AP - Maré, Bonsucesso, Ramos, Penha e Ilha), com exceção dos bairros mais distantes (Vigário Geral, Parada de Lucas, Jardim América e Brás de Pina).
Os diabéticos dos tipos I e II moradores fora da área programática participam da pesquisa enquanto internados.

- Instrumentos utilizados - Utilizaram-se vários instrumentos experimentais no decorrer da operacionalização, porém os aprovados e geradores dos dados tabulados foram:

1) Formulário para levantamento de clientes com a finalidade de identificar o cliente participante do estudo e verificar o grau de conhecimento do mesmo sobre a doença, insulina, autocuidado etc.; este era aplicado após seleção dos clientes que se enquadravam na população alvo e nops critérios estabelecidos.

2) Formulário para visita domiciliar, aplicado quando da realização da visita para, num primeiro contato, avaliar as condições sócio-econômicas e de moradia e, também, levantar os conhecimentos dos familiares sobre a doença. O mesmo roteiro foi empregado para averiguação das condições de adaptação do cliente, após a alta, e os conhecimentos adquiridos por este e por seus familiares.

Cabe ressaltar que quando o cliente residia fora da área programática, o formulário era aplicado aos familiares ainda no período de internação do mesmo.

3) Formulário de coleta de dados, após alta hospitalar, aplicado em visita domiciliar, por uma bolsista de iniciação científica, para avaliação do aprendizado do cliente relativa à orientação recebida durante a hospitalização.

4) Mapa dos locais de aplicação de insulina, afixado na cabeceira do leito, para que o proprio cliente registre o local de aplicação da insulina e se oriente quanto ao rodízio de locais; serve, tambem, como fator de integração acerca do autocuidado realizado entre equipe assistencial e familiares.

5) Cartão de controle de glicosúria e aplicação de insulina - entregue ao cliente alguns dias antes da alta, com a orientação de que, após a mesma, todos os horários, resultadfos de glicosúria, quantidade de insulina e local de sua aplicação deveriam ser registrados, com o fim de ser controlada a aprendizagem no retorno ao ambulatório para consulta médica e de enfermagem.

- Plano de trabalho - Foram estabelecidas quatro fases a serem seguidas. São elas:

1- Fase: Apresentar o projeto de pesquisa em reunião multiproffional de representantes dos diferentes setores envolvidos no trabalho (nutricionistas, medicos, enfermeiros de saúde comunitária, do desenvolvimento, da unidade de internação piloto, bem como assistente social, professores, alunos è monitores de enfermagem), visando a integração destes nas atividades do trabalho; esclarecer a equipe de enfermagem da unidade de internação piloto e levantar, através de entrevista e teste de conhecimentos pré e pós treinamento, os níveis de interesse (área afetiva) e conhecimentos (áreas cognitivas e psicomotora) retidos o diabetes e a assistência. voltada para o autocuidado.

2- Fase: Entrevistar a clientela selecionada para a apresentação dos projetos; obter a aquiescência desta em participar do trabalho; aplicar o formulário para identificação, verificação de conhecimentos, autorização de visitas domiciliar e informação do melhor horário para realizá-lo, assim como indicação da pessoa mais próxima ao cliente que poderia participar do autocuidado. Orientar os clientes internados, através 
da equipe de enfermagem e/ou cessão de livros e manuais, utilização de jogos sobre sinais, sintomas, complicações e cuidados gerais relacionados com a Diabetes, bem como sobre a importância da sua participação no tratamento.

- Convidar clientes e familiares, independentemente da área de moraria, para participarem (juntos ou em separado) de reuniōes semanais com a equipe do projeto para apresentação, demonstração e discussão do autocuidado referente a glicosúria, tipos de medicação, dieta, auto e hetero-aplicação de insulina (técnica de aplicação, cuidados, manutenção e guarda do material e da insulina), exercícios, medidas preventivas, adaptação dos cuidados no regresso ao lar, bem como informação sobre familiares diabéticos em potencial.

- Esclarecer e supervisionar diariamente - todos os membros da equipe - a realização das práticas de auto-aplicação de insulina, glicosúria, anotação no mapa, etc., e registro do nível de desenvoltura do cliente na realização das atividades.

- Entregar o Boletim Dietoterápico ao cliente e colocar o mapa das regiões do corpo para aplicação de insulina na cabeceira da cama, logo que o mesmo estiver em condições de manuseá-lo, propiciando a leitura e o esclarecimento de dúvidas.

- Realizar, através das monitoras de extensão*, visita domiciliar àqueles que residem na área programática, durante a intemação, com prioridade determinada conforme a necessidade do cliente e família. $\mathrm{O}$ objetivo é conhecer a moradia e os familiares, avaliando as condições locais para subsidiar as orientações necessárias.

- Elaborar e entregar ao cliente o cartão de controle da glicosúria e insulina, o cartão de identificação do diabético e o manual educativo sobre diabetes e autocuidado (os dois últimos encontra-se em fase de elaboração).

$\mathrm{Na}$ alta, aprazar, no ambulatório, a data de retorno do cliente para consultas no mesmo dias: da enfermagem, da nutrição e médica, e orientar o mesmo sobre a necessidade de trazer o cartão de controle da glicosúria e insulina para a consulta. Contactar a enfermeira do ambulatório para propiciar os meios de operacionalização da marcação de consultas para a mesma data de retorno.

Funcionando desta $2 \stackrel{2}{-}$ fase do plano:

Após a admissão pela equipe de enfermagem do setor, os monitores detectavam os clientes que necessitavam de visita domiciliar e aprazavam a visita à residência dos mesmos, geralmente nos fins de semana. Durante a visita domiciliar, além da verificação das condições de moradia, dogrupo familiar e/ou comunidade, eram realizadas demonstraçōes de cuidados de enfermagem e treinamento dos presentes para execução destes cuidados. Os familiares de clientes não residentes na área programática eram entrevistadas e orientadas pelos monitores durante a visita hospitalar ao cliente.

Nesse interim, e durante os contatos diários com a equipe de enfermagem, os clientes recebiam livros sobre o Diabetes e eram orientados sobre o autocuidado, a medida da glicosária e a auto-aplicação da insulina. Uma cez por semana a equipe de pesquisa reunia-se com clientes e familiares, inicialmente em sala a parte, e, posteriormente, nas enfermariads onde a equipe passava a orientar e/ou esclarecer dúvidas das questões teóricas e práticas através de discussões,, demonstrações e uso de material ilustrativo. Em consequência as atividades aplicadas eram registradas no plano diário de cuidados, e na evolução de enfermagem, bem como a desenvoltura do cliente. Estes registros são importantes para integrar a equipe de trabalho, evitar deplicação de ações, e permitir o desenvolvimento sequencial do processo educativo, a verificação constante da supervisão da evolução clínica e avaliação do desempenho do cliente no seu autocuidado.

3- Fase: Discutir com a enfermeira da consulta de enfermagem ambulatorial a aplicação do Formulário de Coleta de Dados após Alta Hospitalar na consulta de enfermagem, por ela ou pelos acadêmicos de enfermagem, quando do retorno do cliente ao ambulatorio.

- Verificar o seguimento do tratamento medicamentoso e dietético, reforçar a orientação dada na consulta de enfermagem ambulatorial e determinar a necessidade de realização de outras visitas domiciliares.

Esta fase não consta nos resultados parciais, porém, foi iniciada em março de 89 , com a participação dos alunos de graduação na consulta de enfermagem e visita domiciliar.

4- Fase: Propor ao Hospital que adote a estratégia do autocuidado após a aprovação do resultado por escrito.

- Solicitar a participação do Serviço de Desenvolvimento no sentido de incentivar a comunhão de esforços Çara que o cliente seja o provedor do seu cuidado.

- Formar grupos de auto-ajuda no ambulatório, nas unidades de internação e na comunidade, para se reunirem a fim de trocarem experiências, receberem ensino e até formarem um bazar de venda de materiais e medicamentos para os diabéticos a preço de custo.

\section{APRESENTAÇ̃O, ANÁLISE E DISCUSSÃO DOS RESULTADOS PARCIAIS \\ - Quantitativos}

Para clarificar o entendimento com relação aos resultados foram elaborados 5 (cinco) quadros representativos da clientela atendida no $2^{\circ}$ semestre de 1988 , tanto da área programática como fora da mesma.

\footnotetext{
* Monitoras de Extensão são estudantes contratadas pela Universidade como Bolsistas para atuarem nos projetos de extensão
} 
Os quadros são apresentados a seguir:

QUADRO I - Distribuição dos pacientes diabéticos participantes da pesquisa, por bairro de moradia, tipo de diabetes e visita domiciliar. Período de Julho de Dezembro de 1988.

\begin{tabular}{l|c|c|c|c|c|c}
\hline \multirow{2}{*}{ Diabetes } & Bairro & $\begin{array}{c}\text { Ilha do } \\
\text { Governa } \\
\text { dor }\end{array}$ & Ramos & $\begin{array}{c}\text { Bonsu- } \\
\text { cesso }\end{array}$ & $\begin{array}{c}\text { Fora da } \\
\text { A F * }\end{array}$ & Total \\
\hline Tipo I & Com V.D. & 3 & 1 & 2 & - & 6 \\
\cline { 2 - 7 } & Sem V.D. & 3 & - & 1 & 15 & 19 \\
\hline Tipo II & Com V.D. & 5 & - & 2 & 1 & 8 \\
\hline Ignorado & Sem V.D. & - & - & - & 5 & 5 \\
\hline Total & & 12 & 1 & 5 & 24 & 42 \\
\hline
\end{tabular}

* AP - Á rea Programática

Durante o desenvolvimento do projeto ocorreram 2 6bitos, sendo 01 da AP e outro de fora da mesma. Houve duas recusas: um negou-se a fornecer o endereço para que fosse feita a visita, tendo-se mostrado pouco receptivo no Hospital, em particular, e outro não quis fornecer qualquer dado elucidativo sobre o diabetes, durante a visita domiciliar.

Para a execução de mais de uma visita domiciliar, foram selecionados aqueles que tinham mais dificuldade no aprendizado ou que tinham maiores limitações físicas para se auto-cuidarem. Não foi feita mais de uma visita domiciliar em todos os pacientes da área programática, devido a pouca disponibilidade de tempo das monitoras, dificuldade de transporte para os locais de moradia, bem como, pouca segurança para as mesmas.

A percepção dos monitores durante as visitas domiciliares, com relação ao cliente diabético e seu familiar, foi a seguinte:

- "Famflia em boas condições sócio-econômicas, possibilitando tratamento e controle do Diabetes de bom nível. Grau de conhecimento e orientação em bom nível. Familia parece participar ativamente do tratamento do cliente, ainda assim mantém um bom nível de independência. Embora haja conhecimento, este não segue a dieta";

- "Percebi que a cliente é tratada como uma incapacitada. É preciso que se trabalhe a aceitação da Diabetes pelo cliente e famnia';

- "A família desconhece totalmente os sinais, sintomas e tratamento do diabetes. O marido da cliente mostra muito interesse em aprender a colaborar no tratamento da esposa, no entanto a filha relatou não ter tempo para participar de orientações".

NOGUEIRA \& FONSECA (1977) ressaltam a importância da abordagem familiar para a assistência adequada à saúde, salientando que o ambiente familiar, quer sob o aspecto de relacionamento afetivo-social, quer sob o aspecto físico, constitui, no conjunto, uma das mais poderosas forças que influenciam a promoção, proteção e recuperação da saúde dos indivíviduos.

QUADRO II - Número de familiares participantes da orientação nas visitas domiciliares por bairro - Período de Julho a Dezembro de 1988

\begin{tabular}{c|c|c|c|c|c}
\hline $\begin{array}{c}\text { Número de Visitas } \\
\text { por bairro da } \\
\text { A P }\end{array}$ & $\begin{array}{c}\text { Ilha do } \\
\text { Governa- } \\
\text { dor }\end{array}$ & Ramos & $\begin{array}{c}\text { Bonsu- } \\
\text { cesso }\end{array}$ & $\begin{array}{c}\text { Fora da } \\
\text { A P }\end{array}$ & Total \\
\hline $1-2$ & 3 & - & 1 & 1 & 5 \\
$3-5$ & 3 & 1 & 3 & - & 7 \\
$6-8$ & 2 & - & - & - & 2 \\
\hline Total & 8 & 1 & 4 & 1 & 14 \\
\hline
\end{tabular}

Pelo quadro acima verifica-se que houve participação significativa de familiares durante a orientação dada nas visitas domiciliares, já que em 7 (sete) residências (metade da amostra) obteve-se a participação de 3 a 5 pessoas.

Levantou-se a hipótese de que a frequência de familiares não foi maior porque nos horários em que as visitas foram realizadas, muitos estavam trabalhando.

A participação da familia no preparo para o autocuidado do cliente diabético é fundamental, já que muitas vezes o cliente tem limitações para o autocui- dado como retinopatias, ausência de membros, etc., devendo um dos familiares aprender a executar os cuidados relativos à dieta, medida da glocosúria e/ou aplicação de insulina, bem como manter a regularidade dos mesmos. A visita domiciliar possibilita, conforme NOGUEIRA \& FONSECA (1977), “o conhecimento do indivíduo dentro do seu verdadeiro contexto, caracterizado pelas condições de habitação, ou pelas relações afetivo-sociais entre os vários membros da famnlia, que são alguns dos importantes fatores a serem identificados para a prestação de assistência integral à saúde". 
QUADRO III - frequência de participantes por reunião realizada na unidade piloto para pacientes diabéticos e familiares. Período: Agosto e Dezembro de 1988

\begin{tabular}{|c|c|c|c|c|c|c|c|c|c|c|c|c|c|}
\hline $\begin{array}{l}\text { Datas } \\
\text { das } \\
\text { Reuniōes }\end{array}$ & 10 & $\begin{array}{rr}17 & 24 \\
& \text { Agosto }\end{array}$ & 31 & $14 \quad 21$ & 28 & $\begin{array}{l}05 \underset{19}{19} \\
\text { Outubro }\end{array}$ & 26 & 09 & $\begin{array}{l}16 \\
\text { Nov }\end{array}$ & $\begin{array}{c}23 \\
m b r o\end{array}$ & 30 & $\mid \begin{array}{cc}07 & 14 \\
\text { Dezembro }\end{array}$ & Total \\
\hline $\begin{array}{l}\text { Frequência } \\
\text { de partici- } \\
\text { pação }\end{array}$ & 8 & 5 & 2 & 0 & 7 & 13 & 4 & 3 & 6 & 4 & 4 & 3 & 83 \\
\hline
\end{tabular}

As primeiras sete reuniōes foram realizadas em sala propria, com participação da equipe da pesquisa, e, a partir da oitava, nas enfermarias, devido ao fato de alguns pacientes preferirem não sair destas; para esse fim dividiu-se a equipe de pesquisa entre os grupos de pacientes femininos e masculinos acompanhados dos respectivos familiares.

As reuniões com pacientes diabéticos e seus familiares eram realizadas antes do horário da visita hospitalat, a fim de que se pudesse obter um número maior de participantes, embora isto nem sempre ocorresse. $\mathrm{O}$ dia escolhido para a orientação foi a quarta-feira, de- vido à pouca disponibilidade do grupo de pesquisa e clientela nos demais dias. Percebeu-se que a aprendizagem dos diabéticos e de seus familiares era lenta e gradual, havendo, porém, grande interesse dos mesmos em aprender. Os participantes avaliaram com importantes as discussões, e solicitavam permisão para trazerem outros familiares às reuniōes; em contrapartida, alegaram falta de cursos financeiros para participação mais efetiva. Acredita-se que a orientação ao cliente diabético deve ser uma constante, principalmente pela dificuldade de apreensão das informações dadas.

QUADRO IV - Tipo de autocuidado realizado na Unidade de Internação pelos diabéticos. PeríodoL junho a Dezembro de 1988.

\begin{tabular}{l|cccccc}
\hline Autocuidado & $\begin{array}{c}\text { Medida de } \\
\text { Glico- } \\
\text { súria }\end{array}$ & $\begin{array}{c}\text { Aplicação } \\
\text { de Insul- } \\
\text { lina }\end{array}$ & $\begin{array}{c}\text { Medidas de } \\
\text { Glicosúria } \\
\text { e Aplicação } \\
\text { de Insulina }\end{array}$ & $\begin{array}{c}\text { Não } \\
\text { Exe- } \\
\text { cução }\end{array}$ & $\begin{array}{c}\text { Igno- } \\
\text { rados }\end{array}$ & Total \\
\hline
\end{tabular}

Os motivos que levaram à não execução do autocuidado foram deficiência visual, obnubilação, arteriosclerose, desinteresse, aleŕ da incapacidade de aceitar a auto-aplicação de uma injeção. Em trabalho realizado por MALERBI (1987), em São Paulo, foi constatato que as complicações mais frequentemente encontradas nos 1659 clientes analisados foram: neuropatias periféricas $(38 \%)$, retinopatias $(30 \%)$, coronariopatias $(15 \%)$ e arteriosclerose de extremidades (13\%). Estes resultados demonstram o alto grau de morbidade na população atendida.

Durante o desenrolar do trabalho, percebeu-se tambem que o cliente diabético, enquanto internado, tem dificuldade em aceitar a idéia de que ele próprio deve cuidar de si e assim tornar-se independente da

equipe de saúde. Acredita-se que isto ocorra devido a um "pre-conceito" de que, quando internado, o cliente torna-se "paciente" e deve ser tratado pela equipe de saúde como tal, e segundo suas próprias palavras "tira férias" e gosta de "ser cuidado", o que dificulta a orientação. Outros, já com cegueira ou dificuldade de visão, não tinham condições sequer de medir sua propria glicosúria. MACHADO et alii (1979), em trabalho sobre orientação de enfermagem na auto-aplicação de insulina, relata que, alguns pacientes rejeitaram a idéia da orientação, alegando ter quem lhes fizesse a aplicação. Essa rejeição poderia ser ainda ditada por inúmeros motivos, tais como: falta de interesse, medo, ansiedade, etc.

QUADRO V - Avaliação do grau de conhecimento do cliente diabético na visita domiciliar após a alta, realizada pela bolsista de inicição científica* - Período: julho a Dezembro de 1988.

\begin{tabular}{l|c|c|c}
\hline Assuntos & Conhece & Conhece Parcialmente & Não Conhece \\
\hline Diabetes & - & 8 & - \\
Insulina & 5 & 3 & - \\
Glicosúria & 7 & 1 & 1 \\
Glicemia & 5 & 2 & 5 \\
Hiperglicemia & 2 & 1 & 5 \\
Hipoglicemia & 1 & 2 & - \\
\hline
\end{tabular}

* Bolsista de Iniciaçåo Cientffica: såo estudantes, com coeficiente de rendimento escolar acima de sete (7), interessados em pesquisa, que executam este tipo de trabalho dentro de um projeto ja existente. 
Nota: Com relação ao conhecimento do clientè diabético acerca de sua doença, dividiu-se o tema em conhece, conhece parcialmente e não conhece, da seguinte forma:

- Conhece: sabe o que é a doença, como ocorre, sinais e sintomas, como tratá-la.

- Conhece parcialmente: não sabe definir de for-

Percebeu-se que a dificuldade de apreensão se dá nos pontos referentes à área cognitiva, estando condizentes com os resultados qualitativos das reuniões.

Nos conhecimentos que abrangiam a área psicomotora, como medida de glicosúria e aplicação de in- ma completa o que é a doença, como ocorre, sinais e sintomas e como tratá-la.

- Não conhece: não tem conhecimento algum sobre a doença, como ocorre, sinais e sintomas e como trata-la.

sulina, houve maior facilidade de aprendizagem. Nota-se que o desconhecimento sobre hiper e hipoglicemia poderça ser causado por se tratar de assunto mais abstrato.

\section{- Qualitativos}

$\mathrm{Na}$ análise qualitativa dos dados levantados, citaremos 5 (cinco) questões dos formulários de pacientes, bem como as respostas dadas por estes e por seus familiares em reunião conjunta, antes de terem sido orientados.

1a Questão: Pelas informações que chagaram ao seu conhecimento, diria que a diabetes tem cura?

"Acredito que não tenha cura, mesmo porque, no caso de minha mãe, o fator psicologico é a principal causa de aumento do açúcar no sangue".

"O diabétes não tem cura. Minha irmã também é diabetica e tem muita diferença entre a gente. Tem coisas que ela sente que não sinto e que eu sinto e ela não sente. Tenho um sobrinho diabético que não tem problemas".

'ÇNão tem cura, mas se seguir e fizer as coisas direitinho, dá para viver bem individualmente e socialmente".

'ÇTem cura; se a gente pensar do lado religioso, pode haver um milagre. Mas, colocando o pé no chão dá para conviver com a diabétes. $\mathrm{O}$ diabético deve tomar a decisão de fazer dieta e o tratamento".

Observa-se que a incurabilidade da doença é reconhecida e dois demonstraram que a solução é saber conviver com a patologia. A impossibilidade de cura para o uiabético é algo que requer uma grande luta interior para aceitar. Percebe-se que poucos são aqueles que realmente entendem esta impossibilidade e tentam conviver sem esperança. A maioria se refugia nos esígnios de Deus deixando a seu critério a cura ou não".

2- Questão: Você acredita que a diabétes alterou a economia da familia?

"Se for comprar so produtos dietéticos fica muito caro, mas se souber escolher bem os alimentos permitidos, é possível se alimentar bem e não gastar muito".

"No nosso caso não, porque temos uma situação econômica razoável. Mas acredito que para muita gente se ja muito difícil uma dieta propícia".

"A dieta é muito cara, mas a vida é curta e temos que tirar proveito dela, por isso, sempre que posso, eu compro produtos dietéticos".

"Sim porque a dieta fica muito cara, por exemplo, os produtos dietéticos são caríssimos. $\mathrm{O}$ ideal seria que tofdos os diabéticos pudessem ser orientados quanto a dieta para as possíveis substituições. Acredito que muitos não possam fazer a dieta por problemas econômicos".

"Altera muito. O Clinitest custa quatrocentos e poucos cruzados. Ainda dá para levar, pois recebo do INPS"

Nota-se a ênfase dada aos produtos dietéticos que no entanto não são essenciais, podendo a familia fazer uso de dieta única.

Sendo o diabetes uma doença cara, é importante que se ensine este clientela utilizar cuidados e técnicas alternativas de controle, como uso do reativo de $\mathrm{Be}$ nedict, reutilização da seringa e agulha, substituição de alimentos, cuidados adequados com o corpo, etc.

3 Questão: Você estaria disposto a acompanhar o tratamento do seu familiar diabético?

"Sim, e acho muito válido encontros como este".

"Também sou diabético e gostaria de aprender mais. Estou aprendendo a aplicar a insulina. Eu não tenho problema, não sigo a dieta. Minha irmã, ela tem muita força de vontade. Lá em casa todo mundo fala para ela comer porque não sente nada".

"Sim, eu gostaria de aprender muito mais, pois ele sabe muito, mas guarda tudo para si".

"Sim, estou disposto a colaborar com o tratramento de minha esposa e dar apoio, mas depende exclusivamente dela. Isso que está acontecendo aqui é um sonho. Sonho porque isto que está acontecendo aqui, não acontece em lugar nenhum".

Os familiares desejam reuniōes para esclarecimentos e orientação de como lidar com a problemática de seus diabéticos, porém isto depende do grau de desenvolvimento da famnlia.

Para haver participação da famnlia na doença é necessário que esta esteja organizada, e num grau de amadurecimento tal, que permita operacionalizar as soluções para seus problemas.

A ef etividade do acompanhamento só vai ocorrer se os familiares tiverem oportunidade de reforçar o aprendizado através da repetição de orientações na unidade de internação, visita domiciliar e consulta de enfermagem.

4" Questão: Você tem conhecimento das complicações decorrentes do não seguimento do tratamento prescrito?

"Estou com uma inflamação no olho e acho que por causa do diabetes e tenho dormência nas pernas e 
acho que é de diabetes tambêm. Emagreci muito, estou pesando $28 \mathrm{Kg}$. A médica disse que assim não posso continuar, tenho que engordar aos poucos".

"Há várias complicações de rins, visão, feridas que não cicatrizam, fígado, estômago, stress e sexual. Há 10 anos, a mãe dele aplicou uma insulina com uma agulha que pensou estar esterilizada e ấ apareceu um tumor no braço dele. Ele veio rapidamente aqui para o hospital e foi logo tratado. O médico disse que se não tivesse corroido a tempo, ele podia ter ficado sem o braço".

Sei que ocorre problemas de circulação, dormência, problemas inflamatórios nos orgãos genitais alterações no sistema nervoso, os diabéticos são muito retraídos. Enfim, eu acho que o diabetes atinge todo o organismo, seria mais fácil falar o que ele não causa. Deveria haver mais esclarecimentos e propaganda. É um problema tão sério quanto a AIDS, mas existe uma descrença muito grande por parte das autoridades responsáveis".

Estas respostas mostram a ansiedade para obter maior orientação sobre a patologia e a necessidade de reuniões para o esclarecimento de dúvidas e apreensões.

Vale ressaltar o último registro citado, da necessidade de maior divulgação, na imprensa escrita e falada, como está ocorrendo com a AIDS, sobre as complicações e sobre a conduta a ser adotada para melhor convívio com a doença e descoberta precoce.

$\mathrm{O}$ terceiro registro demonstra a necessidade de ensinamentos práticos da aplicação de insulina, treino e supervisão frequente, do cliente e seus familiares.

5^ Questão: Você tem conhecimento da dieta específica para o diabético?

"Conheço a dieta, sei que não devo comer massas, alguns legumes, não posso beber refrigerantes e comer pão. Sigo a dieta".

"Não pode comer beterraba e cenoura. Fica diffcil fazer a dieta pela falta de conhecimento tanto da doença como da importância da própria dieta".

"ÇMeu marido não é muito de doce, não costuma comer muito, é difícil. Eu tinha 150 de glicose, tomei um remédio por cinco dias e ele me fez muito mal. Me mandaram fazer dieta. Já estive uma vez sem forças e os médicos me deram doce e melhorei. Já tomei chá de flor de jambo. Eu não sei bem qual é a dieta. Para mim é não comer muita massa, doce, não tomar coca-cola. Eu só largo o cafezinho".

"Sei qual é a dieta, mas minha esposa não segue fielmente por achar muito dificil. Talves porque ela não esteja totalmente conscientizada da importância. Ela já frequentou uma colónia de férias de diabéticos, mas mesmo assim ainda abusa".

"ÇAcho muito difícil fazer comida separado. Eu gosto de refrigerantes. Não conheço o dietético. Quando tenho paciência, eu faço saladas".

as declarações denotam falta de: conhecimento das substituiçőes alimentares, estímulo para seguí-la e compreensão dos familiares, pois não há necessidade de alimentação separada para o diabético por ser ela adequada ao ser humano em geral.

MILCHOVICH \& DUNN (1984) relatam que os requerimentos básicos nutricionais de um paciente diabético são os mesmos das pessoas não diabéticas. Isto significa que o diabético deve apenas prestar atenção à qualidade e à quantidade do que come. Os diabéticos, na sua maioria, gostam muito de doces, tortas, caramelos, etc. e têm grande dificuldade em evitá-los, mesmo bem orientados. Neste ponto, deve entrar a orientação da nutricionista, para ensinar os diabéticos e familiares quais são os alimentos adequados, quais os não adequados, bem como a melhor forma de substituir uns por outros.

VIGGIANO (1987) refere que o "nutricionista como um profissional essencialmente educador, em todos seus planos de ação, age em relação ao diabéti$\mathrm{co}$, avaliando a situação e arquitetando estratégias para educação e mudança de comportamento de seus clientes em relação à aceitação da doença e seu controle".

Durante os questionamentos, percebeu-se que a maior preocupação do cliente diabético e seu familiar é a obediência à dieta indicada, já que a maior parte não tem condição sócio-econômica que permita segui-la adequadamente. É difícil aos familiares compreender que a dieta do diabético é saudável e equilibrada e que eles também poderão ser diabéticos em potencial, e que, sendo assim, sర lucrarão em mudar os seus hábitos alimentares para prevenção da doença e ajuda familiar ao diabético; mas, infelizmente, por deficiência de pessoal, as nutricionistas não estavam disponíveis à tarde, no horário das reuniōes com pacientes e familiares, para darem a orientação necessária.

A orientação aos pacientes era feita na unidade de internação, isoladamente, e era entregue, na véspera da alta, o boletim dietoterápico. Foi solicitado à nutricionista do setor que distribuisse o boletim dietoterápico logo que o paciente chegasse à unidade de internação, de forma que o mesmo pudesse obter esclarecimentos, assim que o manuseasse, enquanto internado.

verificou-se, também, que o diabético no dia-adia não utiliza-se os testes de glicosúria (clinitest, glicofita e reativo de Benedict), como rotina. Ele toma a dosagem de insulina de acordo com os sintomas ou segue a precrição médica sem a preocupação de estar tomando a quantidade correta ou não. Cabe à equipe de enfermagem esclarecer melhor o uso, guarda e finalidade e até como obter ou substituir a medicação.

A clientela que frequênta o Serviço, não tem condições financeiras para comprar o material necessário para estes testes, bem como para troca de seringas e agulhas com frequência. A orientação é dada para que seja utilizada seringa de vidro, que deverá ser fervida em estojo proprio ou em vasilhame somente usado para este fim, para reutilização posterior. Orienta-se, também, no sentido da seringa e a agulha descartáveis serem guardadas no congelador, após o uso com técnica asséptica, envolta no próprio protetor, podendo serem reutilizadas até 10 vezes; outra forma de conservação é a imersão do material (seringa e agulha) no alcool, em recipiente com tampa. trocando-se o alcool a cada semana e fervendo-se, nesta oportunidade, a seringa e a agulha. MACHADO et alii (1979), ZAGURY (1984), RODRIGUES (1988).

Dos dois métodos citados, com uso de agulha descartável, o que é mais recomendado é ao da manutenção da seringa e agulha no congelador VOLPATTO et alii (1986), POTEET et alii (1987). 


\section{DIFICULDADES ENCONTRADAS DURANTE A PESQUISA}

1) Falta de transporte para os locais de diffdil acesso, o que contribui para um maior gasto de tempo nas visitas domiciliares. (grupo de pesquisa).

2) Não cumprimento, pelo cliente, do tratamento prescrito para o diabetes, principalmente em relação à dieta e aos testes de glicosúria, devido à baixa condição sర́cio-econômica de muitos diabeticos e não fornecimento do material pelas instituições de saúde.

3) Pouca disponibilidade da equipe de saúde em participar do preparo para o autocuidado do cliente diabético e de seu familiar.

4) Pouca participação de familiares nas reuniões devido a falta de condições financeiras para o transporte, pelas reuniōes se realizarem no horário de trabalho dos mesmos e, também por dificuldade de comunicação do Serviço Social com as familiares.

5) Dificuldade de aceitação da mudança de comportamento assistencial dos profissionais de saúde, diante da teoria do autocuidado, devido a sua pouca utilização na prática, nas instituições de saúde.

\section{CONCLUSÕES}

É fundamental incluir o cliente, seus familiares e/ou amigos, e colegas de trabalho na orientação e nas demonstrações de aplicação de insulina, medida de glicosúria, identificação e socorro quando da hipo e hiperglicemia, composição de alimentação, prevenção e detecção de possível diabético e hipertenso no grupo familiar e/ou comunidade, bem como na prevenção das complicações do Diabetes.

A orientação e as demonstrações devem ser pautadas nas reais condições do cliente, de sua moradia e nas dificuldades de apreensão demonstradas, nas áreas cognitiva, psicolotora e afetoiva (nível de escolaridade, presença de deficiência físicas, negação da doença, etc.), para o bom aproveitamento e a efetiva participação no autocuidado.

Engajar acadêmicos de enfermagem em programas voltados para o autocuidado do cliente e cooperação da famnlia é ampliar em muito, seus conhecimentos, e levá-lo à reflexão sobre a prática assistencial; da mesma forma, é conduzir os enfermeiros à "desrobotização" na assistência, propiciando uma postura participativa, que priorize a mudança de comportamento do cliente diante de sua patologia e valorize os componentes do seu meio ambiente.

\section{REFERÊNCIAS BIBLIOGRÁFICAS}

BRASIL - Ministério da Saúde. Secretaria Nacional de Programas Especiais de Saúde. Divisão Nacional de Doenças Crónico-Degenerativas. Programa Nacional de Educação e Controle do Diabetes Mellitus - PNECD - Brasflia - DF, 1988.

2 JODZINSKY, M. Diabetes mellitus, por que educar? In: Educação em Diabetes, Editor Laerte Damasceno, Vitoria: Unigrafic, 1987, p. 11-14.

3 MACHADO, M.N. et alii. Orientação de enfermagem na auto-aplicação de insulina. Rev.Bras. Enf. , Brasflia, 32 (2): $167-75,1979$.

4 MALERBI, D. Diferentes nfveis de complexidade no atendimento ao paciente diabético: a necessidade de descentralização. In: Educação em Diabetes, Editor Laerte Damasceno, Vitória: Unigrafic, 1987. p. 29-37.

5 MENDES I.A.C. Observação da administração de insulina em pacientes diabéticos no domicflio. Rio de Janeiro, 1975, p. 50-70 (Tese de Mestrado - Escola de Enfermagem Anna Nery/UFRJ).

6 MILCHOVITCH, S.K.\& DUNN, B.L. Diabete: o que você deve saber. Rio de Janeiro: Atheneu, 1984. p. 20-21.

7 NORONHA, R. Experiência participativa mobilizadora de enfermagem; condiçōes prévias para o autocuidado. Rev. Bras. Enf., Brasflia: 39 (1): 34-43, fev./mar. 1986.

8 NOGUEIRA, M.F.C. \& FONSECA, R.M.G.S. da. A visita domiciliária como método de assistência de enfermagem a famflia. Rev. Bras. Enf. USP, 11(1): 28-50, abr. 1977.

9 OREM, D.E. Nursing theories' the base of professional nursing practice. Prentice-hall, New Jersey: 1980. p. 90-106.

10 PERRASSE, A.V. O planejamento de um programa de educação em diabete. In: Educação em Diabetes. Editor Laerte Damasceno, Vitória: Unigraf, 1987. p. 25-28.

11 POTEET, G.W. et alii. Outcome of multiple usage of disposable syringes in the insulin-requiring diabetic. Nurs. Res., 36(6): 350-2, nov/dec., 1987.

12 RODRIGUES, A.A. et alii. Diabetes mellitus. Manual elaborado pelo Hospital Govemador Israel Pinheiro - IPSEMG, BH, MG, 1988. p. 14-19.

13 THIOLLENT, M. Metodologia da pesquisa-ação، 3 ed. são Paulo: Cortez, 1986. p. 14-18.

14 VIGGIANO C.E. Educação em diabetes: participação do nutricionista na equipe multidisciplinar de saúde. In: Educação em Diabetes, Editor Laerte Damasceno, Vitória, Unigraf, 1987. p. 60-61.

15 VOLPATГО A. et alii. Manual de Orientação a pacientes portadores de Diabetes Mellitus. Revista Gaúcha de Enfermagem. Porto Alegre, 7 (2): 325-335, jul. 1986.

16 ZAGURY, L., ZAGURY, Г., GUIDACCI, J. Diabetes sem medo. Rio de Janeiro: ed. Rocco, 1984, p.7-90. 